\title{
Cyanobacteria Bioactive Compound, their Production and Extraction with Pharmaceutical Applications - A Review
}

\author{
Sparsha Pattnaik and Lakshmi Singh* \\ Department of Botany, College of Basic Science and Humanities, \\ Orissa University of Agriculture and Technology, Bhubaneswar, Odisha, India \\ *Corresponding author
}

A B S T R A C T

\begin{tabular}{l} 
Key w o r d s \\
Sub-aerial \\
cyanobacteria, \\
Bioactive \\
molecules, \\
Antimicrobial \\
agents, Production \\
and extraction, \\
Pharmaceutical \\
applications \\
\hline Article Info \\
\hline $\begin{array}{l}\text { Accepted: } \\
\text { 26 May } 2020 \\
\text { Available Online: } \\
\text { 10 June } 2020\end{array}$ \\
\hline
\end{tabular}

\section{Keywords}

Sub-aerial

cyanobacteria

Antimicrobial

Pharmaceutical

Article Info

Accepted:

Available Online

10 June 2020
Bio-active compounds are of high aesthetic value in pharmaceutical industries but they are not widely explored. These compounds derived from plant, fungi and bacteria cannot really satisfy even a small fraction of the existing demand of the growing population day by day. In recent years, there is a great deal of attention towards cyanobacteria as they are a vast reserve of bioactive molecules with wide pharmaceutical importance. Extremophiles cyanobacteria have the ability to endure extreme conditions and posses a great capacity for producing biologically active compounds that are capable of meeting the global demand as an alternative source of drugs with economic sustainability. Thus, approaches for making extremophiles cyanobacteria as therapeutic agents specifically focused on antimicrobial activities can hold a scintillating future in scientific research to get invested in the field of pharmaceuticals as well as for industrial applications.

\section{Introduction}

In past few years, due to exponential rise in population and changing lifestyles, microorganisms have developed resistant against many drugs which are used in treating many infectious diseases. Multi drug resistance is the resistance of microorganisms against the targeted drugs (Tanwar et al., 2014). The prolonged use of antibiotics, over or under use of antibiotics, use of antibiotics without any information regarding antibiotic sensitivity pattern of the pathogens, non completion of doses etc. have lead to the development of MDR among pathogens for the treatment of diseases. According to WHO report $80 \%$ of the world population gamble on plants for traditional medicines and $40 \%$ of the industries depend on plants to produce drugs (Jain, 2017). However, many challenges have been lined up regarding the pharmaceutical application of plants which 
include authentication of plant material, large scale industrial output of bioactive products from plants to meet the never ending demands of brimming population (Bijauliya et al., 2017). This necessitates a demand for discovery of antimicrobial compounds from microorganisms.

Among microorganisms, Algae have a significant attraction as natural source of bioactive molecules with broad range of biological activities such as antibiotics, antiviral, antitumoural, antioxidant and antiinflammatory (Devi and Mehta, 2016; Hassouani et al., 2017; Bule et al., 2018). Algae are swiftly proving to be an extremely important source of biologically active secondary metabolites (Ramya and Muralitharum, 2019) which could be used for the biological control of pathogens. Secondary or primary metabolites of algae consist of diverse group of chemical compounds. Report on antibiotic activity of algae was first reported by Pratt et al., (1944). Cyanobacteria natural products are considered to be one of the accessible origins in the microbial world which are useful to humankind in several ways due to their potential application (Lau et al., 2015; Demay et al., 2019). The widespread distribution of these organisms reflect the tolerance of cyanobacteria towards environmental stress due to their morphological and broad spectrum of specific properties in physiology (Uzair et al., 2012; Nguyen et al., 2017; Soa and Samuel, 2018; Godlewska et al., 2019). Generally, microorganisms forming microbial mats in extreme environment have been recently identified as a good source of bioactive compounds for different biotechnological applications (Bhatnagar and Kim, 2010). Modern research has focused on a variety of bioactive compounds produced by cyanobacteria from various biotypes and has been tested for antimicrobial activity e.g marine (Kumar et al., 2019) and terrestrial
(Safavi et al., 2019). Considering sub-aerial ecosystem as an extreme environment (due to adverse condition and nutrient depletion, few studies have yet identified the antibacterial potential of cyanobacteria isolates from this habitat (Panigrahi et al., 2015; Sahu et al., 2017; Pattnaik and Samad, 2018; Bhakat et al., 2020) still however no studies till date are adequate. Several researchers have investigated bioactive compounds with a diverse range of biological activities and chemicals structures including novel cyclic and linear lipopetides, fatty acids, alkaloids and other organic chemicals (Singh et al., 2016; Bule et al., 2018).

\section{Bioactivity of compounds extracted from cyanobacteria}

Cyanobacteria earlier known as blue green algae are photosynthetic prokaryotes among the oldest extant organisms on Earth, dating back to fossil records of nearly 3.5 billion years. These organisms have been identified as a new and rich source of bioactive compounds (Abed et al., 2009; Shalaby, 2011; Nowruzi et al., 2017).

Reports available indicate that bioactive compounds contradict synthetic drugs in their composition and their arrangement of radicals and atoms. They are much more potent in inhibiting protein-protein interactions resulting in effective immune response, signal transduction; mitosis and ultimately apoptosis without causing much harm to living organisms (Koehn and Carter, 2005; Guaadaoui et al., 2014). However, few compounds like hassallidin, hapalindole and $Y$ - lactone isolated from Nostoc sp. CENA 219 KP701037 and Nostoc calcicula 6sf Cale KP701034, Fischerella sp. and Scytonema sp. (Shishido et al., 2015; Singh et al., 2016) have attained importance for their antimicrobial activity in the field of biotechnology. Still further research needs to 
be carried out to isolate bioactive compounds possessing antimicrobial property from cyanobacteria for betterment of the society. Cyanobacteria can be potential source of such compounds which may have haemolytic or anti-haemolytic effect on human erythrocytes. Therefore, many of the cyanobacteria species need to be evaluated for their potential haemolytic activity to be categorized as a safe remedy to cure diseases.

\section{Biosynthesis of bioactive compounds in cyanobacteria}

Bioactive compounds can be broadly categorized into terpenes, alkaloids, fatty acids, UV-absorbing compounds, peptides and polyketides etc. Peptide biosynthesis in cyanobacteria occurs through ribosomal and non-ribosomal pathways (Marahiel and Essen, 2009) shown in (Fig. 1). Cyanobacterial polyketide consists of cis- and transacyltransferases. The cis- polyketide synthase have repetitive acyltransferases. The transpolyketide have non-repeatative acyltransferases. Only one acyltransferase can be repeated several times. There are three types of polyketide synthase (Type - I, II and III), out of which Type - II and III work in a repetitive manner and synthesize aromatic compounds (Hertweck, 2009; Piel, 2010; Helfrich et al., 2014). Non-ribosomal peptides are synthesized through non-ribosomal peptide synthetases (NRPS). One amino acid molecule is added to the growing amino acid chain by each NRPS module (Fischbach and Walsh, 2006; Kehr, et al., 2011; Marahiel, 2016). An adenylation (A) domain, a peptidyl carrier protein and a condensation (C) domain are needed for the activation and identification of the amino acid, (PCP) to move the amino acid, to make the peptide bond respectively. In addition, thioesterase (TE) domain plays a key role in releasing the final compound and terminates chainelongation.

\section{Decision-making factors for production and extraction of bioactive compound from cyanobacteria}

Sub-aerial cyanobacteria grow on exposed surface of walls of building facades, monuments and temples (Cutler and Viles 2010; Rossi et al., 2012; Keshari and Adhikary, 2014). They are found in abundance in tropical climate rather than temperate climate due to their ability to withstand adverse environmental conditions like high light intensity, high temperature, and drought conditions. They produce bioactive compounds to have a favourable growth when they are subjected to stress conditions. Environmental factors like culture age, temperature, salinity, $\mathrm{pH}$, macro and micronutrients and light play a key role in manufacturing bioactive compounds (Noaman et al., 2004). The most important requirement for obtaining bioactive compound from subaerial cyanobacteria is selection of standard extraction and purification protocol (Fig. 2). Mass cultivation of axenic culture of subaerial cyanobacteria with maximum biomass for small scale production can be carried out in conical flasks or small photo bioreactors with $\mathrm{pH}$ of media 7.0-9.0, light intensity 2800-3000lux and temperature $28^{\circ} \mathrm{C}$. The environmental conditions may vary depending on the type of species and specific substratum. Among various artificial media, blue green eleven (BG-11) media (Rippka et al., 1979) was considered more suitable to obtain maximum yield.

Strategies for large scale biomass production of sub-aerial cyanobacteria and bioactive compound with pharmacological utility

Scientific research is always focused to find its application for human welfare. Therefore, any study relating to its application must aim 
two things. One is its safety to human beings or the target host and secondly its cost effectiveness. Researchers and academicians over the Globe have always tried to use different novel techniques to produce value added products with low cost. The cost of extracting bioactive compounds from cyanobacteria can be minimised by using a photobioreactor and improving the efficiency of cyanobacteria through genetic engineering. The entire process of bioactive compound extraction can be cost effective by increasing physiological and environmental factors through optimization of extraction protocol with respect to culture media, $\mathrm{pH}$, temperature and cell disruption technique etc. (Fig. 2) favouring bioactive compounds production (Chisti, 2007). There are two types of photobioreactor: open bioreactors and closed photobioreactor. But for bioactive substances having pharmacological utility, mostly closed bioreactors are preferred to avoid contamination (Singh et al., 2005). With the advent technologies, emphasis have been given to the molecular level i.e. the genes working behind the bioactive compounds production can be enhanced through recombinant DNA technology as represented in (Fig. 3).

\section{Diversity of sub-aerial cyanobacteria on extreme environments and their importance in Bhubaneswar and Puri, Odisha}

Cyanobacteria are mediated as being one of the potential organisms, instituting a versatile group of microorganisms and residing in diverse habitat ranging from alkaline hot spring to permanent snow fields in the poles can be profitable to mankind in multidirectional ways. They constitute a principal group of organisms for biotechnological exploitation, especially for valuable products, processes and services, with important impact in food and pharmaceutical industries as well as in public health. In recent years, a number of significant advancements have occurred in Cyanobacterial biotechnology from natural resources like marine, freshwater, and very few terrestrial etc. Odisha one of the mega diversified tropical states where $90 \%$ of inhabitants gamble on agriculture for their sustenance and people predominantly trust on customary medication for healing many diseases is beautified with many temples, monuments and building facades bearing historical importance. In Tropical regions of Odisha, especially Bhubaneswar $\left(20^{\circ} 29^{\prime} 61^{\prime} ' \mathrm{~N}, \quad 85^{\circ} 82^{\prime} 45^{\prime}, \mathrm{E}\right)$ and Puri $\left(19^{\circ} 81^{\prime} 34^{\prime}\right.$ 'N, $85^{\circ} 83^{\prime} 15^{\prime}$ ' E) which are considered as historically important places, the exterior surfaces of temples, monuments as well as building facades are the residence of microorganisms. Twenty six sampling sites were analyzed for biofilms and crusts sample from old/new buildings temples and monuments for the cyanobacterial diversity which is represented in Map (Fig. 4). The study revealed occurrence of 28 species belonging to six genera, five families and 3orders. Dominated Cyanobacteria of these two areas are mainly Scytonema, Tolypothrix and Lyngbya (Fig. 5 \& 6). Other associated organisms are found be Phormidium sp., Westiellopsis sp. and Nostoc sp. Such cyanobacteria inhabiting extreme environments can be rightly called as subaerial cyanobacteria and due to their ability to endure extreme conditions, these organisms have been known as "Extremophiles". Extremophiles thrive on the edge of temperature, $\mathrm{pH}$, pressure, hyper salinity, dryness and desiccation. Research so far has shown that these organisms' posses a great capacity for producing biologically active compounds because of their special growing conditions, their survival and mechanisms that are not found in marine and freshwater species. Some scientists believe that more harsh and extreme conditions lead to a wider 
production of a diverse range of more or less, specific substances thus pointing towards these organisms as brilliant candidates for biotechnological application.
In earlier studies, cyanobacteria isolated from marine and freshwater with their biologically active compounds are well endowed (Singh $e t$ al., 2005; Madhumati et al., 2011; Srikong et al., 2015).

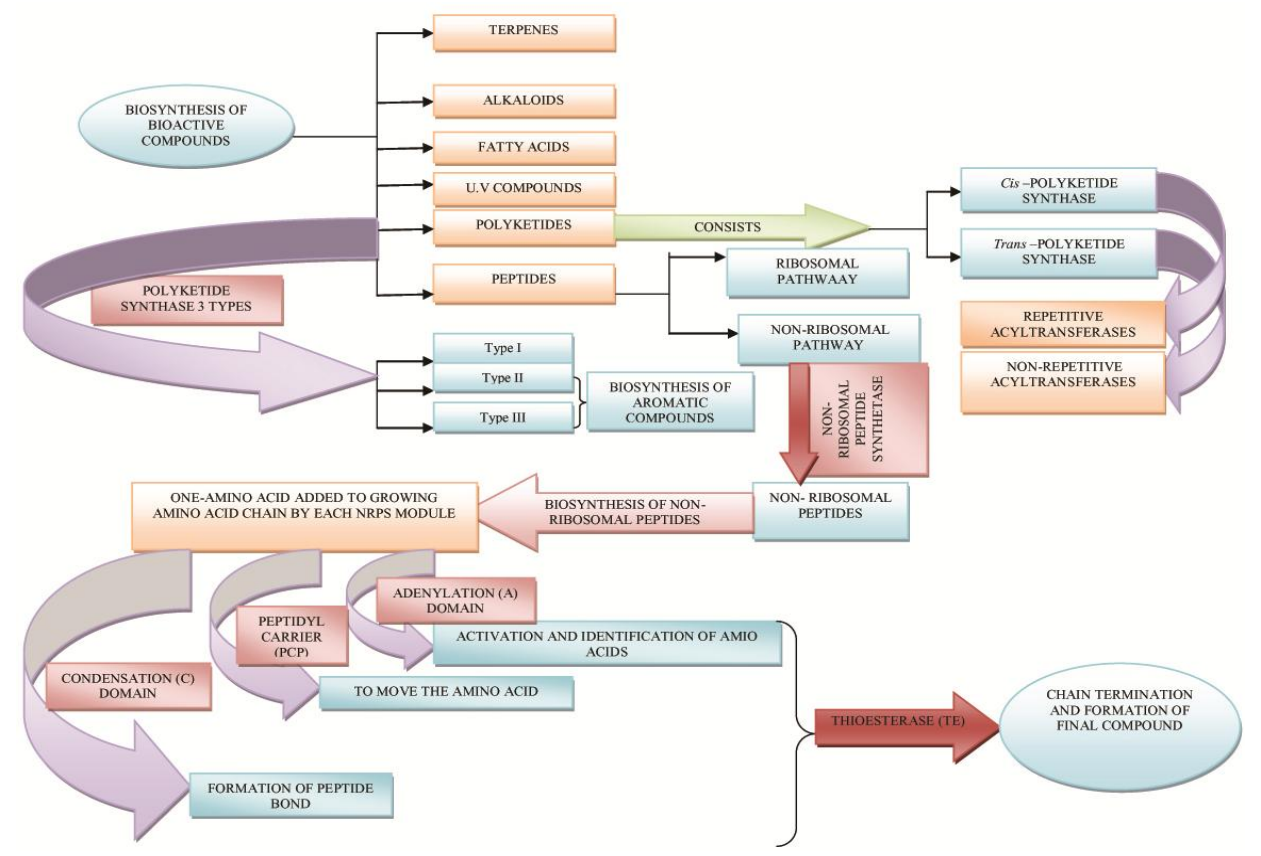

Fig.1 Flow chart showing the biosynthesis pathway of the bioactive compounds in cyanobacteria (Kultschar and Llewellyn, 2018)

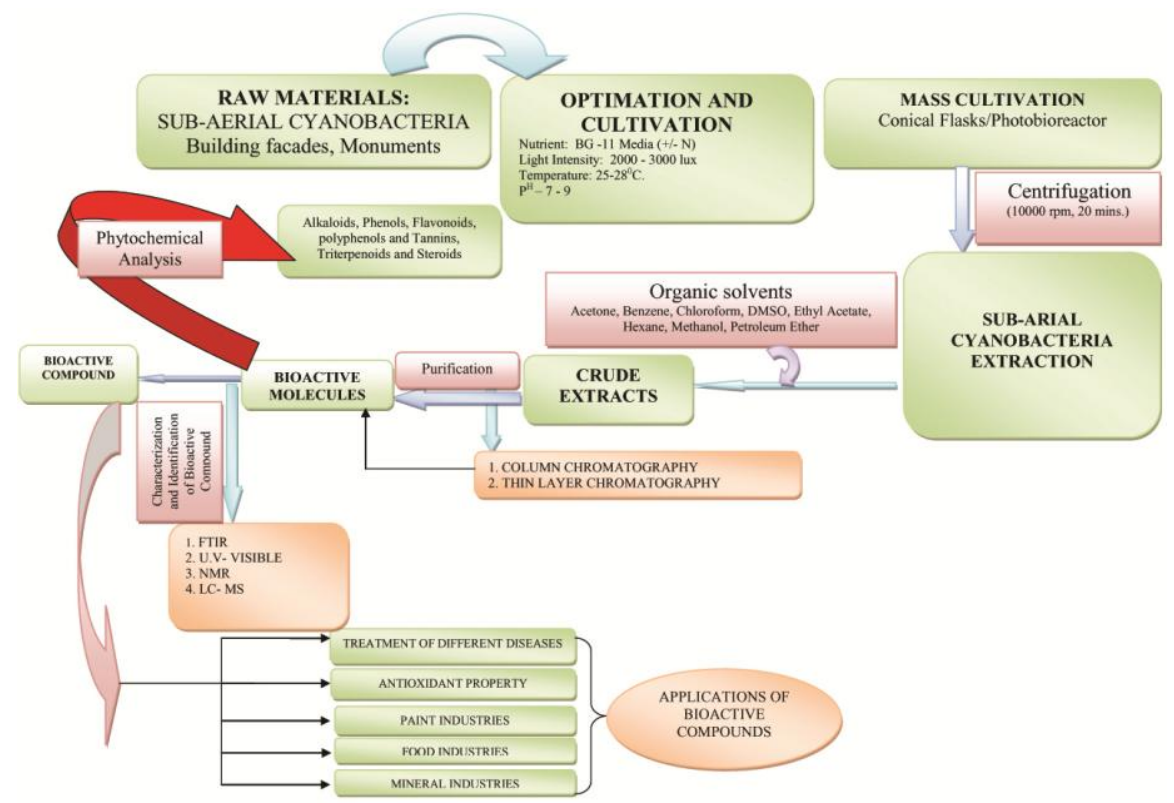

Fig.2 Traditional strategy investigated for production and extraction of bioactive compounds from cyanobacteria (Delattre et al., 2016) 


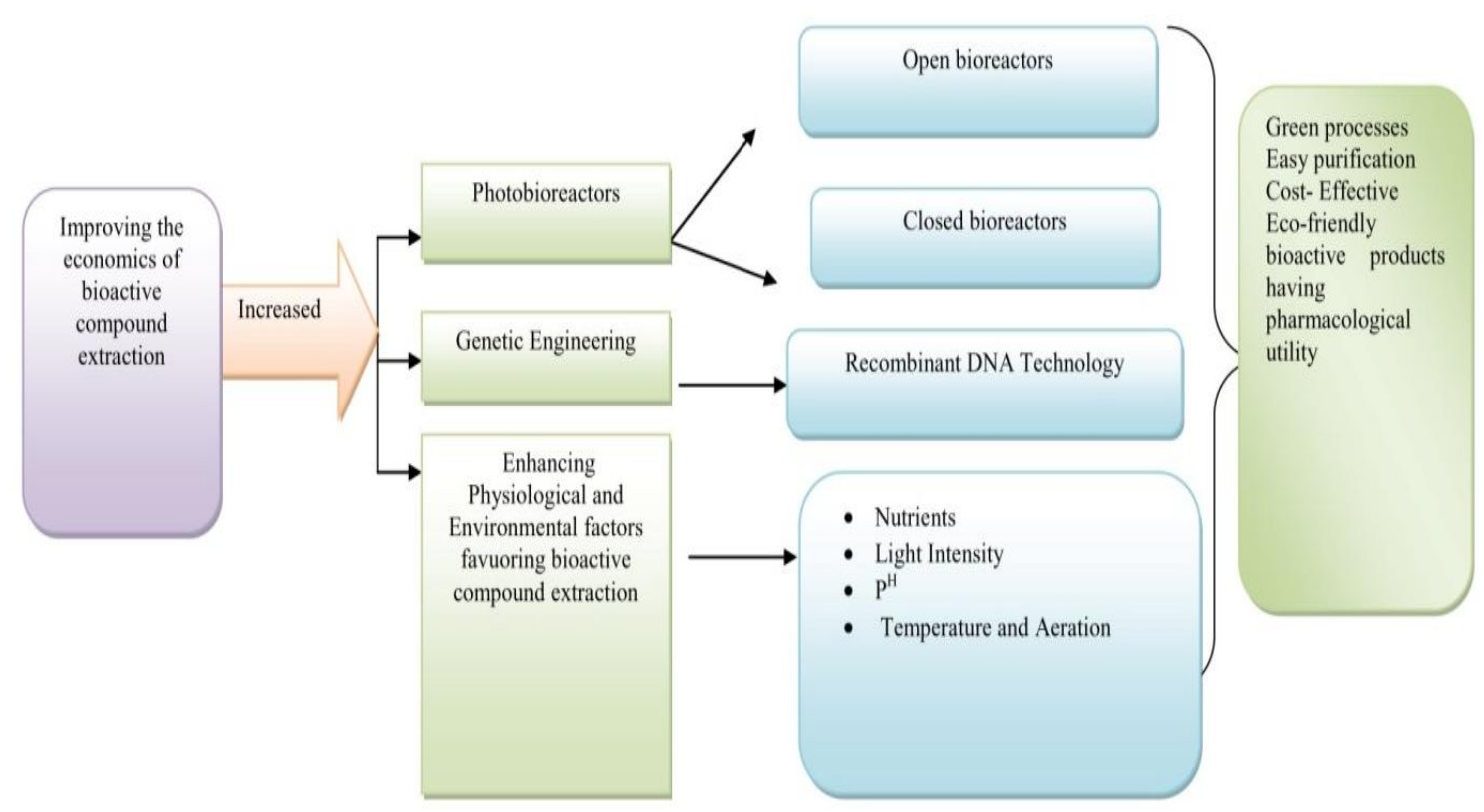

Fig.3 Flow chart for improving economics of cyanobacteria bioactive compound in pharmacological utility (Delattre et al., 2016)

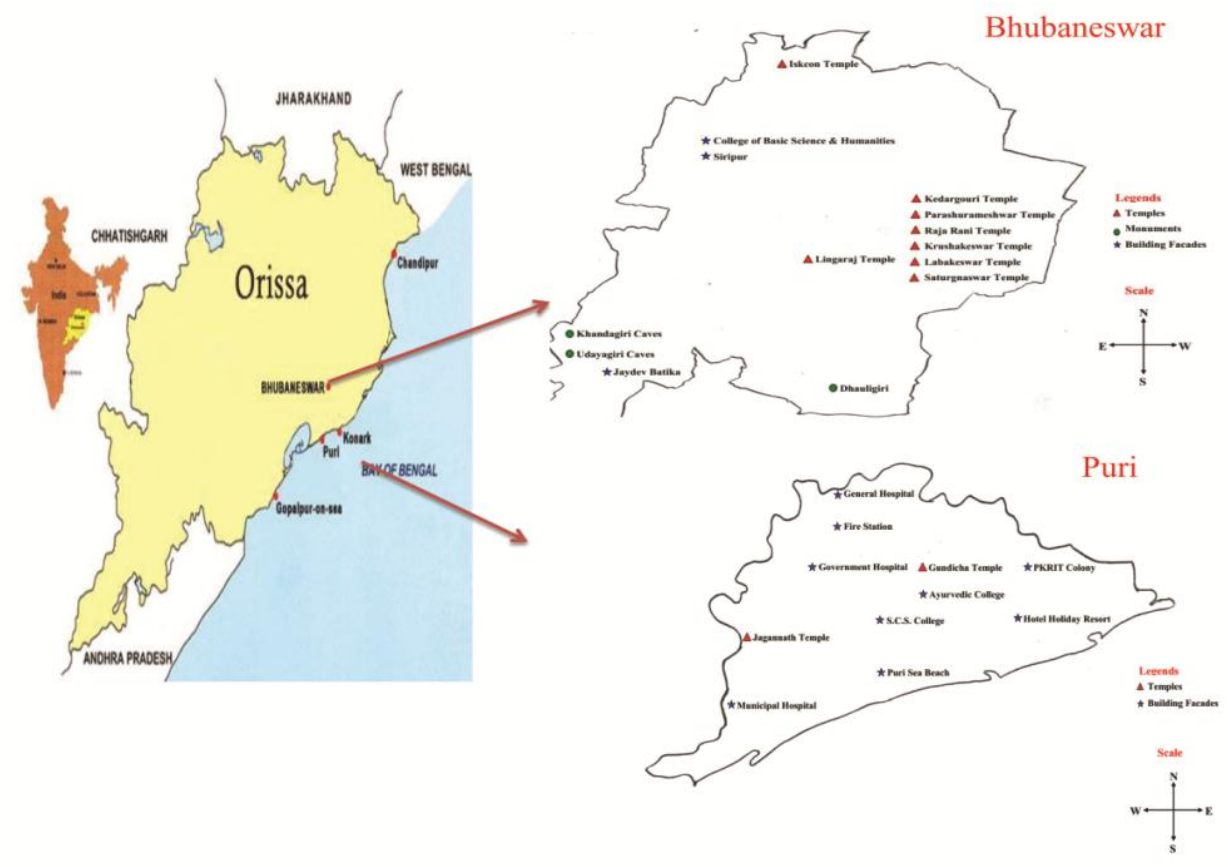

Fig.4 Map showing Bhubaneswar and Puri of Odisha where cyanobacteria samples were collected Bhubaneswar and Puri 


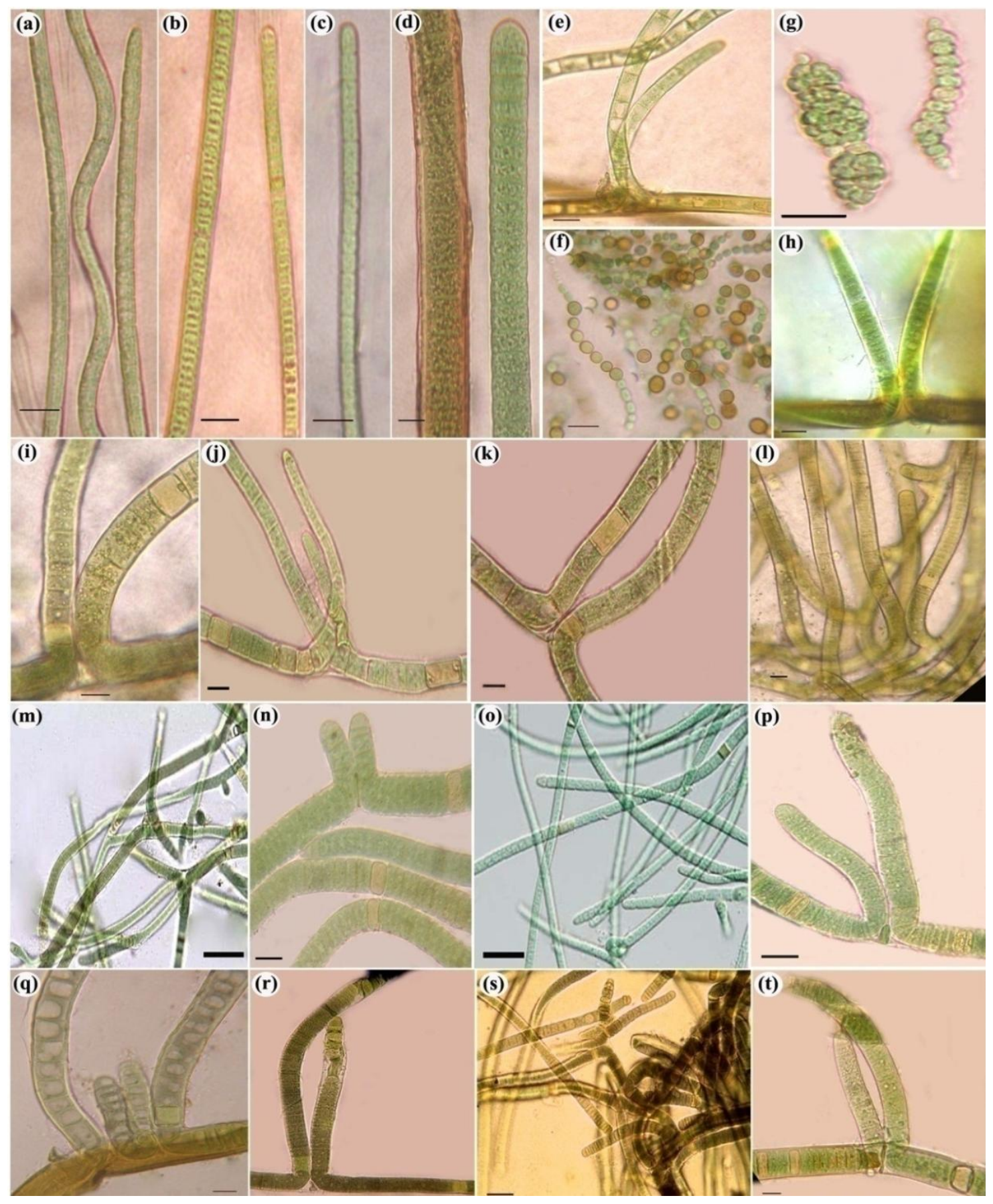

Fig.5 Microphotographs of sub-aerial cyanobacteria isolated from the exterior surface of different sites (Building facades, temples and monuments) of Bhubaneswar and Puri, Odisha. (a) Phormidium autumnale, (b) Phormidium ambigum, (c) Phormidium retzii, (d) Lyngbya kuetzingiana, (e) Leptolyngbya sp., (f) Nostoc linkia, (g) Nostoc punctiforme, (h) Scytonema bohneri, (i) Scytonema crispum, (j) Scytonema geitleri, (k) Scytonema pseudohofmanii, (1) Scytonema hofman-bangii, (m) Scytonema hyalinum, (n) Scytonema stuposum, (o) Scytonema multiramosum, (p) Scytonema schmidtii, (q) Scytonema pseudoguyanensis, (r) Scytonema punctatum, (s) Scytonema ocellatum and (t) Scytonema mirabile. Scale bar: Fig. A-t $=10 \mu \mathrm{m}$ 

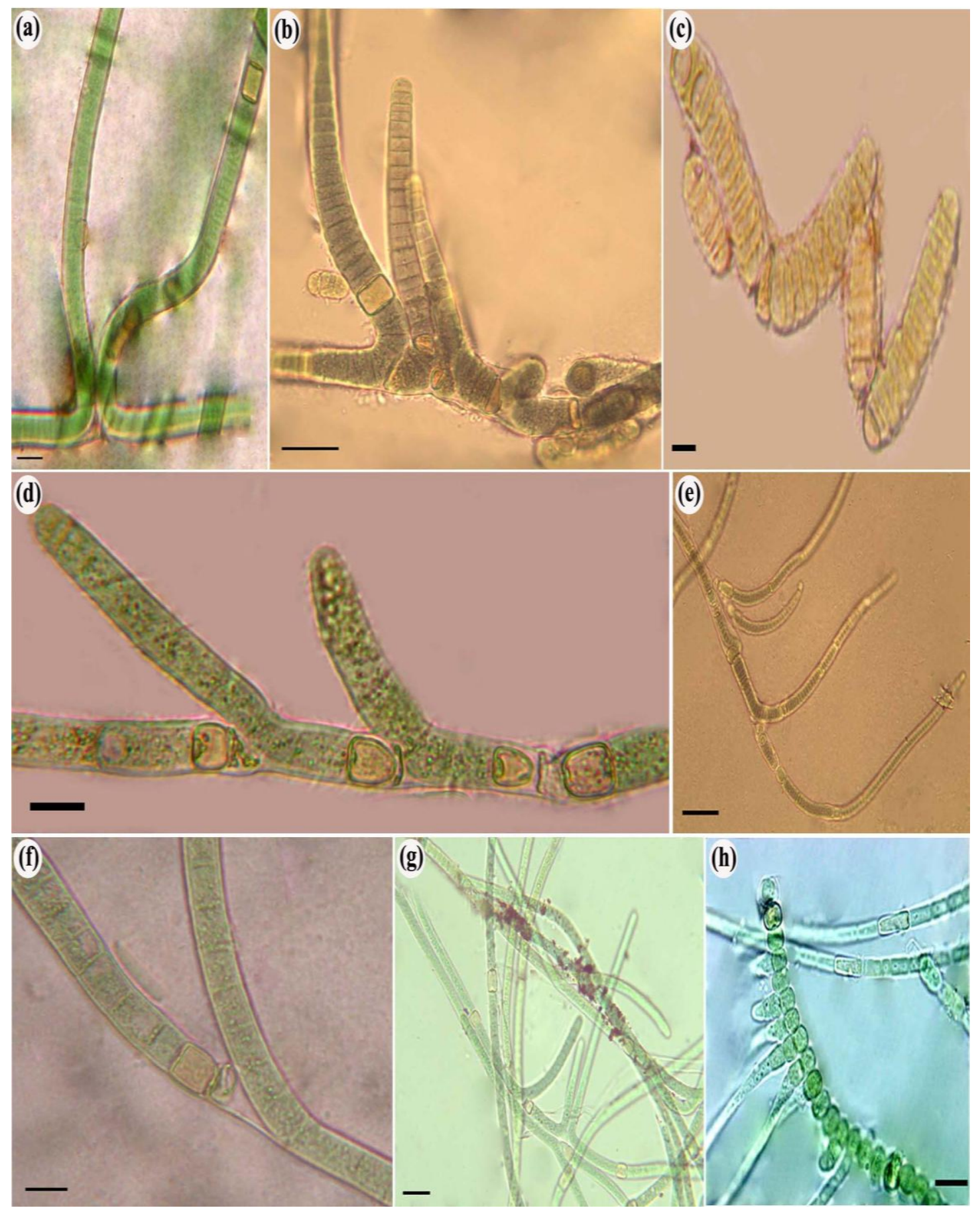

(h)

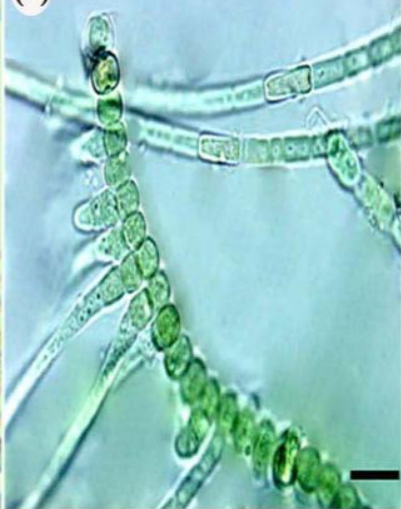

Fig.6 Microphotographs of sub-aerial cyanobacteria isolated from the exterior surface of different sites (Building facades, temples and monuments) of Bhubaneswar and Puri, Odisha. (a)

Scytonema sp., (b) Scytonema sp., (c) Hassallia byssoida, (d) Tolypothrix distorta, (e) Tolypothrix rechingeri, (f) Tolypothrix tenuis, (g) Fischerella sp., and (h) Westiellopsis prolifica. Scale bar: Fig. a-h $=10 \mu \mathrm{m}$

Sub-aerial cyanobacteria are demonstrated to be one of richest sources of novel biological compounds having biotechnological implications which are yet to be investigated. Keeping in view the beneficial aspects of these microorganisms especially in 
pharmaceutical field, the cyanobacterial flora from building facades and monuments of Bhubaneswar and Puri in the state of Odisha can be taken into account for exploration as remedial drugs against many human diseases. To the best of our knowledge, very little scientific investigations have been carried out deal specifically with extremophilic cyanobacteria and their biological activities (Drobac et al., 2007; Lamprinou et al., 2015; Kultschar and Llewellyn, 2018). Moreover, sporadic reports are available on isolation of sub-aerial cyanobacteria from the monuments and building facades in the state of Odisha with their antimicrobial activities (Samad and Adhikary, 2008; Adhikary and Kovacik, 2010; Keshari and Adhikary, 2014; Keshari et al., 2015). However, no effective steps on biologically active compounds of extremophiles cyanobacteria have been employed as an antimicrobial agents isolated from sub-aerial surface of building facades and monuments has been reported for which search is on.

In conclusion, exploration of new natural products as antimicrobial agents against resistant pathogens is very important for clinical medicine and public health. The subaerial cyanobacteria have the ability to endure extreme conditions and possess a great capacity for producing biologically active secondary metabolites which might be benefit directly or as supplements to curb human diseases. Thus modern research should be intensified having effective, non-toxic, ecofriendly natural bioactive compounds which can be exploited in the field of Pharmaceutical industries. Sub-aerial habitat of Odisha is rich in diverse cyanobacteria. So far little work has been done on the bioactive compound of sub-aerial cyanobacteria. So in this study we have undertaken to assess the diversity of sub-aerial cyanobacteria and their production and extraction of bioactive compounds.

\section{Future prospective}

Cyanobacteria are the promising sources of useful natural products. There is indeed a wide range of applications of Cyanobacteria in biotechnology. There is great potential to further exploit the rich Cyanobacterial resources of Odisha for various biotechnological applications. Presently, the isolation of number of natural products is increasing. However few compounds have reached the market. Limited number of identified Cyanobacterial biomolecules and analogues are in clinical trials and some of them have passed phases of clinical trials to prove them as potential drugs. In order to discover the new opportunities available, there is demanding need for extensive research in their new emerging field of drug exploration which should be regarded as a priority area of research in Odisha.

\section{Acknowledgement}

The authors are thankful to Department of Science and Technology, Government of Odisha for providing financial aid as well as Head of the Department of Botany and the Director, College of Basic Science and Humanities, Odisha University of Agriculture and Technology for allocating lab facilities to conduct the research work.

\section{Funding}

This work is supported by Department of Science and Technology, Government of Odisha.

\section{References}

Abed, R.M.M, Dobrestrov, S. and Sudesh K. 2009.Applications of Cyanobacteria In Biotechnology. Journal of Applied Microbiology, 106(1): 1-12.

Adhikary, SP. and Kovacik, L. 2010. Comparative Analysis Of Cyanobacteria 
And Microalgae In The Biofilms On The Exterior Of Stone Monuments In Bratislava, Slovakia And In Bhubaneswar, India. Journal of Indian Botanical Science, 89(1\&2):19-23.

Bhakat, S., Saha, S., Mandal, S., Rath J. 2020. Antibacterial activity of desiccated cyanobacterium Anabaena sp. isolated from Terracotta Monuments of Bishnupur, West Bengal. International Journal of Pharma Science and Drug Research, 12(2):1333.

Bijauliya, R.K., Alok, S., Chanchal, D.K. and Kumar, M. 2017. A Comprehensive Review on Standardization of Herbal Drugs. International Journal of Pharmaceutical Sciences and Research, 8(9): 3663-3677.

Bule, M.H., Ahmed, I., Maqbool, F., Bilal, M. and Iqbal, H M. N. 2018. Microalgae as a source of high-value bioactive compounds. Frontiers in Bioscience Scholar, 10:197-216.

Chisti, Y. 2007. Biodiesel from microalgae. Biotechnology Advances, 25:294-306.

Cutler, N. and Viles, H. 2010. Eukaryotic Microorganisms and Stone Biodeterioration. Geomicrobiology Journal, 27(6-7):630-646.

Delattre, C., Pierre, G., Laroche,C. and Michaud,P. 2016. Production, Extraction and Characterization of Microalgal and Cyanobacterial Exopolysaccarides. Biotechnological Advances, 34(7): 1159 1179.

Demay, J., Bernard, C., Reinhardt, A. and Marie, B. 2019. Natural Products from Cyanobacteria: Focus on Beneficial Activities. Marine Drugs, 17 (320): 1-49.

Devi, KM., Mehta, SK. 2016. Antimicrobial Activity and GC-MS Analysis of Fresh Water Cyanobacterium, Fischerella ambigua. World Journal of Pharmaceutical and Medical Research, 2(5):199-208.

Drovac-cik, A.V., Dulic, T.I., Stojanovic, D.B. and Svircev, Z.B. 2007. The Importance Of Extremophiles Cyanobacteria In The Production of Biologically Active
Compounds. Natural Product Sciences. 112: 57-66.

Fischbach, MA. and Walsh, CT. 2006. Assembly-Line Enzymology for Polyketide And Non Ribosomal Peptide Antibiotics: Logic, Machinery, And Mechanisms. Chemical Reviews, 106(8): 3468-3496.

Godlewska, K., Michalak, I., Pacyga,P., Baśladyńska, S. and Chojnacka, K. 2019. Potential Applications Of Cyanobacteria: Spirulina Platensis Filtrates And Homogenates In Agriculture, World Journal of Microbiology and Biotechnology, 35 (80): 1-18.

Guaadaoui, A., Benaicha, S., Elmajdoub, N., Bellaoui, M and Hamal A. 2014. What is a bioactive compound? A Combined Definition for A Preliminary Consensus. International Journal of Nutrition and Food Sciences, 3(3): 174-179.

Helfrich, EJN., Reiter, S. and Piel J. 2014. Recent Advances In Genome-Based Polyketide Discovery. Current Opinion in Biotechnology. 29: 107-115.

Hertweck, C. 2009.The biosynthetic logic of polyketide diversity, Angewandte Chemie International Edition, 48(26): 4688-4716.

Hassouani, M., Sabour,B., Belattmania, Z., ElAfouani, S., Reani, A., Ribeiro, T., Castelo-Branco R., Ramos, V., Preto M., Costa, P.M., Urbatzka, R., Lero,P. and Vasconcelos, V. 2017. In-vitro Anticancer, Antioxidant And Antimicrobial Potential of Lyngbya Aestuarii (Cyanobacteria) From Atlantic Coast Of Morocco, Journal of Materials and Environmental Sciences, 8 (S) : 4923-4933.

Jain, S.K. 2017. Medicinal Plants, Pleione, 11(1): 176.

Kehr, J.C., Picchi, DG and Dittmann, E. 2011. Natural Product Biosyntheses In Cyanobacteria: A Treasure Trove Of Unique Enzymes. Beilstein, Journal of Organic Chemistry, 7: 1622-1635.

Keshari, N. and Adhikary, S.P. 2014. Diversity of Cyanobacteria on Stone Monuments And Building Facades Of India and Their 
Phylogenetic Analysis. International Biodeterioration and Biodegradation, 90: 45-51.

Keshari, N., Das, SK. and Adhikary, SP. 2015. Identification Of Cyanobacteria Species With Overlapping Morphological Features By 16S Rrna Gene Sequencing. European Journal of Phycology, 50(4):15.

Koehn, FE. and Carter, GT. 2005. The Evolving Role Of Natural Products In Drug Discovery. Nature Reviews Drug Discovery, 4(3): 206-220.

Kultschar B and Llewellyn C. 2018. Secondary Metabolites in Cyanobacteria. Secondary Metabolites- Sources and Applications, Chapter-2: 24-36.

Kumar, S., Marketo, M., Andreja, K.,Katrina,D.,Jan,H.and P.Hrouzek. 2019. Antimicrobial Activity And Bioactive Profiling of Heterocytous Cyanobacterial Strains Using MS/MS-Based Molecular Networking, Folia Microbiologia, 64: 645-654.

Lau, NS., Matsui, M., and Abdullah, A.A. 2015. Cyanobacteria: Photoautotrophic Microbial Factories for The Sustainable Synthesis Of Industrial Products, BioMed Research International, 2015: 1-9.

Lamprinou, V., Tryfinopoulou, K., Velonakis, E.N., Vatopoulos, A., Antonopoulou, S., Fragopoulou, E., Pantazidou, A., and Amilli, AE. 2015. Cave Cyanobacteria Showing Antibacterial Activity. International Journal of Speleology, 44(3): 1-9.

Madhumathi, V., Deepa, P., Jeyachandran, S., Manoharan, C. and Vijayakumar, S. 2011. Antimicrobial Activity Of Cyanobacteria Isolated From Freshwater Lake, International Journal of.Microbiological Research, 2 (3): 213-216.

Marahiel, MA and Essen, LO. 2009. Chapter 13. Nonribosomal Peptide Synthetases Mechanistic and Structural Aspects Of Essential Domains. Methods Enzymology, 458: 337-351.

Marahiel, MA. 2016. A Structural Model for Multimodular NRPS Assembly Lines.
Natural Products Reports, 33(2):136-140.

Noaman, NH., Fattah, A., Khaleafa, M. and Zaky, SH. 2004. Factors affecting antimicrobial activity of Synechococcus leopoliensis. Microbiology Research, 159 (4):395-402.

Nowruzi, B., Haghighat, S., Fahimi, H. and Mohammadi, E. 2017. Nostoc Cyanobacteria Species: A New And Rich Source of Novel Bioactive Compounds With Pharmaceutical Potential. Journal of Health Services and Research, 9(1): 5-12. Nguyen, XH., Sumimoto, S.and Suda, S. 2017. Unexpected High Diversity of Terrestrial Cyanobacteria from The Campus Of The University Of The Ryukyus, Okinawa, Japan, Microorganisms, 5(69):1-13.

Panigrahi, S., Sethi, AK. and Samad, LK. 2015. Antibacterial Activities of Scytonema hofman Extracts against Human Pathogenic Bacteria, International Journal of Pharmacy and Pharmaceutical Science, 7(5): 123-126.

Pattnaik, S and Samad, L.K. 2018. Spectral Analysis of Biologically Active Compounds And Antibacterial Activity Of Scytonema Ocellatum Isolated From Sub-Aerial Habitats. International Journal of Current Research, 10(9): 73218-73224.

Piel, J. 2010. Biosynthesis of Polyketides By Trans-AT Polyketide Synthases. Natural Products Report, 27(7): 996-1047.

Pratt, R.., Daniels, T.C., Eiler, J.B., Gunnison, J.B. and Kumler, W.D. 1944. Chlorellin, An Antibacterial Substance. from Chlorella, Science, 99(2754): 351-352.

Ramya, VP. and Muralitharan, G. 2019. Evaluation of Antibacterial Activity Of Cyanobacteria Isolated From Fresh Water Ecosystem Of Tiruchirappalli, District, Tamil Nadu, India, Research journal of Life science, Bioinformatics. Pharmaceutical and Chemical Sciences, 5(2): 331-344.

Rippka,R.,Deruelles,J.,Waterbury,J.B.,Herdma, M. and Stanier, R.Y. 1979. Generic Assignments, Strain Histories And Properties of Pure Culture Of 
Cyanobacteria. Journal of General Microbiology, 111: 1-61.

Rossi, F., Potrafka, R. M., Garcia-Pichel, F. and De Philippis, R. 2012. The Role of The Exopolysaccharides In Enhancing Hydraulic Conductivity of Biological Soil Crusts. Soil Biology and Biochemistry, 46: 33-40.

Safavi, M., Nowruz,i B., Estalak,i S., Shokri, M. 2019. Biological Activity Of Methanol Extract From Nostoc sp. N42 And Fischerella sp. S29 Isolated From Aquatic and Terrestrial Ecosystems. International Journal of Algae, 21:373391.

Sahu, E., Giri, D., Bhakta, S., Panda, S.K. and Bastia, A.K.2017. Phytochemical Screening of a Corticolous Cyanobacterium Hassalia byssoidea Hass. Ex Born. Et Flah. For Antibacterial and Antioxidant Activity. World Journal of Pharmacy and Pharmaceutical Sciences, 6(3): 1161-1172.

Sao, S. and Samuel, K. 2018. Study Of Cyanobacteria As Biofertilizer From The Rice Field, World Journal of Pharmaceutical Research, 4(3):16961706.

Samad, L.K. and Adhikary, S.P. 2008. Diversity of Micro-algae and Cyanobacteria on Building Facades and Monuments in India. Algae, 23(2): 91-114.

Shalaby, E. 2011. Algae As Promising Organisms For Environment and Health. Plant Signaling and Behaviour,
6(9):1338-13350.

Shishido, TK., Humisto, A., Jokela, J., Liu, L., Wahlsten, M., Tamrakar, A., Fewer, D P., Permi, P., Andreote, A PD., Fiore, MF., and, K. 2015. Antifungal Compounds from Cyanobacteria. Marine Drugs, 13(4): 2124-214.

Singh, S., Kate, BN. And Banerjee, UC.2005. Bioactive Compounds from Cyanobacteria and Microalgae: An Overview. Critical Review of Biotechnology, 25(3):73-95.

Singh, J. S., Kumar, A., Rai, A. N., and Singh, D. P. 2016. Cyanobacteria: A Precious Bio-Resource In Agriculture, Ecosystem, and Environmental Sustainability. Frontier Microbiology, 7:529.

Srikong, W., Mittraparp-arthorn, O., Rattanaporn, $\mathrm{P}$ and Bovornreungroj, $\mathrm{N}$. 2015. Antimicrobial Activity of Seaweed Extracts from Pattani, Southeast Coast Of Thailand. Food and Applied Bioscience Journal, 3(1): 39-49.

Tanwar, J., Das, S., Fatima, Z. and Hameed, S. 2014. Multidrug Resistance: An Emerging Crisis. Interdisciplinary Perspectives on Infectious Diseases, 2014: 1-7.

Uzair, B., Tabassum, S., Rashed, M.and Rehman, S.F. 2012. Exploring Marine Cyanobacteria For Lead Compounds Of Pharmaceutical Importance. The Scientific World Journal, 2012: 1-10.

\section{How to cite this article:}

Sparsha Pattnaik and Lakshmi Singh. 2020. Cyanobacteria Bioactive Compound, their Production and Extraction with Pharmaceutical Applications - A Review. Int.J.Curr.Microbiol.App.Sci. 9(06): 3394-3405. doi: https://doi.org/10.20546/ijcmas.2020.906.402 